\title{
Impact of truss girder geometrical imperfections on roof bracing load
}

\author{
Piątkowski Michał ${ }^{1, *}$ \\ ${ }^{1}$ Koszalin University of Technology, Faculty of Civil Engineering, Environmental and Geodetic Sciences, Śniadeckich 2, 75-453 \\ Koszalin, Poland
}

\begin{abstract}
The author has presented in this paper his own experimental research on the maximum value and distribution of load in transverse roof bracing caused by a planar truss girder with geometrical imperfections. The tests were performed on $7.0 \mathrm{~m}$ long test models of steel truss made of square hollow sections. The tests performed verify standard recommendations concerning adoption of uniformly distributed notional load of transverse roof bracing and confirm the relations indicated in the discussed literature. The experimental research results were cross-checked by relevant numerical analysis. A comparison of notional loads recommended by the standard and literature with test results was performed and conclusions were formulated.
\end{abstract}

\section{Introduction}

Use of steel trusses as main structures in hall objects is a very economic solution due to high in-plane stiffness of truss girders. Such stiffness originates, first and foremost, from large spacing of truss chords connected by proper web members. Additionally, the space that occurs between the chords allows for placement of installation elements inside the hall roof structure.

Unfortunately, planar trusses feature low out-ofplane stiffness, which causes a need to stabilise their compressed chords by side supports. In the case of compressed top chords, these supports are shaped mostly as a transverse roof bracing (intermediate support) or by connection of the chord with roof trapezoidal sheet (quasi-continuous support) [1, 2]. In both cases such bracings must feature not just proper load bearing capacity but also sufficient stiffness to limit the buckling lengths of the compressed chord [3, 4]. Impact of stiffness of transversal bracings on truss chord buckling lengths was confirmed experimentally and described in $[5,6]$.

A classic computational model of a compressed truss chord supported by an intermediate bracing is the Winter's model. In this model, the compressed chord is analysed as a separate spring-supported column compressed by an invariable force. Geometrical imperfections in the Winter's model were considered, among other, in [7], whereas in [8] the results of computation of the classical Winter's model were compared with 3D numerical analysis performed for a certain planar truss.

Transverse roof bracings carry horizontal loads that originate mostly from wind pressure on given object's gable wall. According to the standard [9] during designing of bracing, additional load originating from geometrical imperfection of the roof girder upper truss chord featuring parabolic shape with maximum
$e_{0}=L / 500$ ( $L-$ truss length) must be taken into account. The standard guidelines recommend substitution of the chord's geometrical imperfection by adoption of a uniformly distributed notional load $q$ taking into account the number of braced trusses $m$ ( $\alpha_{\mathrm{m}}$ coefficient) and the second order effects $\delta_{q}$ from load $q$ and external load. Both distribution of the notional load and formulae compatible with standard [9] are presented at Figure 1.

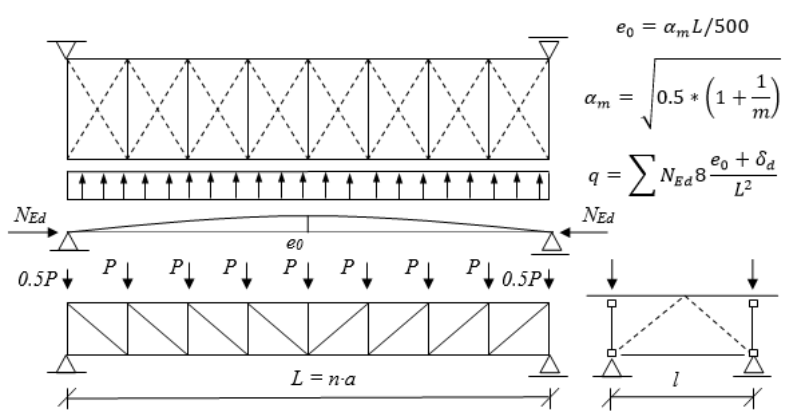

Fig. 1. Standard-indicated notional load of transverse roof bracing originating from a girder with imperfections

The standard rules originate from an analogy between a compressed column with geometrical imperfection and a parabolic arch loaded with uniformly distributed load. However, many factors such as:

- quasi-parabolic force distribution in the compressed chord,

- interaction between the compressed chord with web members and the stretched chord,

- lack of verticality of webs originating from the top chord imperfections,

- simultaneous bottom chord imperfections,

- elastic deformation of the truss caused by external load, have been disregarded.

In recent years, many researchers have proved analytically that those factors have significant impact on the magnitude, and first and foremost, on the

* Corresponding author: michal.piatkowski@tu.koszalin.pl 
distribution of the substitute load $q[10,11,12]$. In these articles the sign-change character of the substitute load originating from a stepped changing chord compressive force and lack of verticality of webs, was demonstrated. Formulae presented in [10] (Fig. 2) allow for taking into account both a diverse distribution of the force in the compressed chord and a diverse shape of chord imperfections $\left(F_{\varphi}\right)$ as well as a lack of verticality of webs $\left(F_{\phi}\right)$.

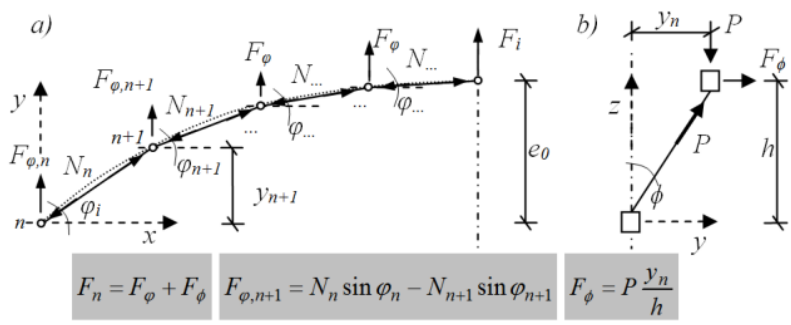

Fig. 2. Bracing load as per [10]

The notional load model shown in [11] allows for determination of the distributed load function, which is particularly valuable e.g. in the event of use of trapezoidal sheet as the bracing. The more specific notional load model presented in [11], together with the relations is presented in Figure 3.

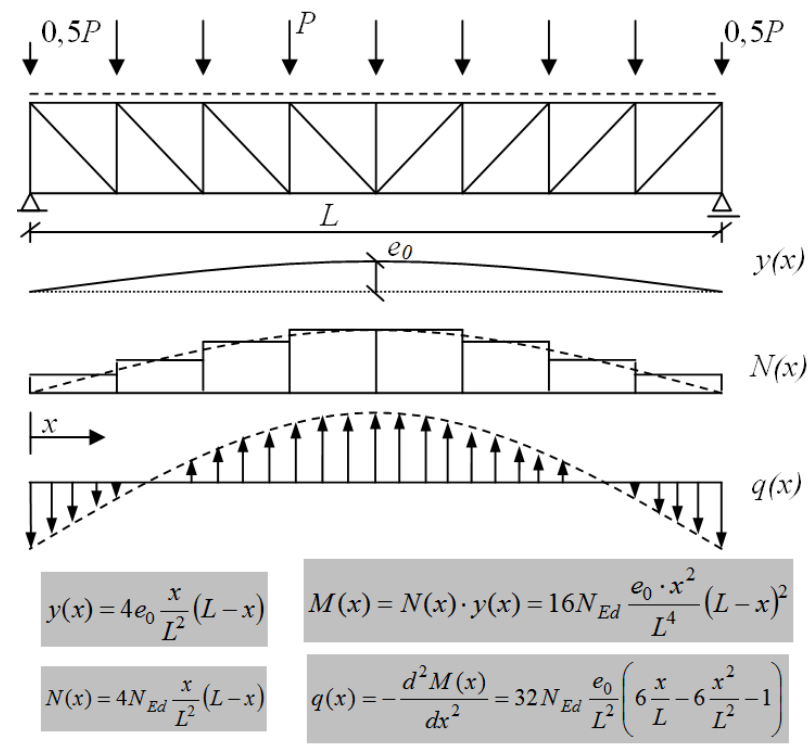

Fig. 3. More specific notional load model as per [11]

However, the relations indicated in [10 and 11] were not confirmed experimentally until now.

\section{Experimental research}

The relations demonstrated by the authors of [10] were verified during author's own experimental research performed on ten $7.0 \mathrm{~m}$ long truss models. The models were made in accordance with the scheme shown in Figure 4. Square hollow sections and welded connections of V-type webs with chords were used. A single span, freely supported static scheme of the truss and gravitational load $P$ applied to the top chord joints were applied.

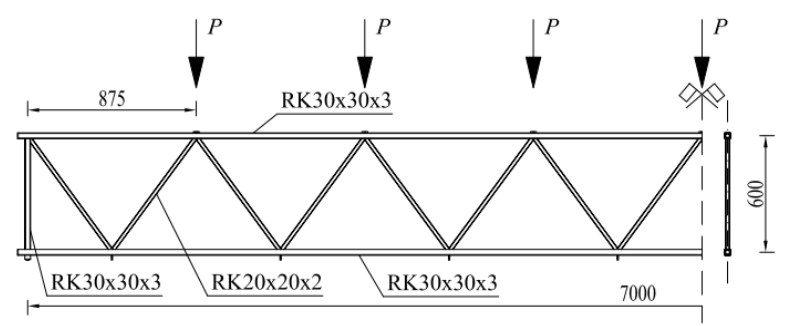

Fig. 4. Test model scheme

The model placed at the test stand (Fig. 5) was laterally supported in each upper chord joint as well as in the middle and outermost joints of the bottom chord. To simulate the truss and bracing connection, a rigid method of lateral support of the truss joints was assumed due to horizontal displacement.

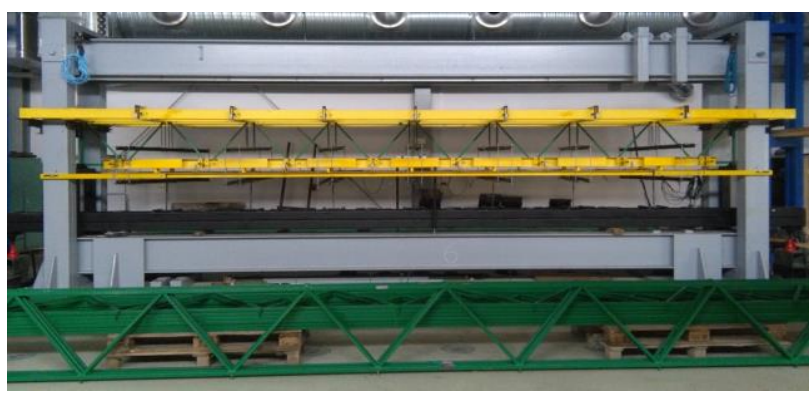

Fig. 5. Test stand and models

Selected joints were supported with a specially designed support that would allow for measurement of the force transmitted to the support with simultaneous freedom of displacement of vertical joint and its rotation. Six force sensors of $2.0 \mathrm{kN}, 5.0 \mathrm{kN}$ and $10.0 \mathrm{kN}$ ranges were used. The sensors recorded both compressive (+), as well as tensile (-) forces with $0.001 \mathrm{kN}$ accuracy. The sensors were located in accordance with the anticipated distribution of force action on side supports. To limit the number of sensors, symmetry of the test model was utilized (Fig. 6). Structural details of the applied side supports are presented in Figure 7. Horizontal displacement LVDT sensors were also installed at the force measurement point to check support susceptibility due to displacement. Sensors with measurement range 300.0 $\mathrm{mm}$ and accuracy of $0.001 \mathrm{~mm}$ were used. The sensors were fitted in such way, so that measurement of horizontal displacement in both directions could be effected. Deflection of the truss in the middle of its span was also detected.

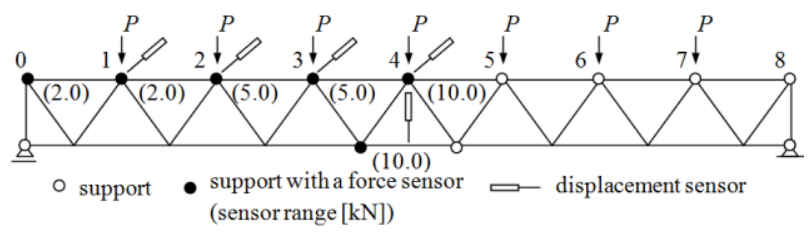

Fig. 6. Force and displacement sensors locations 


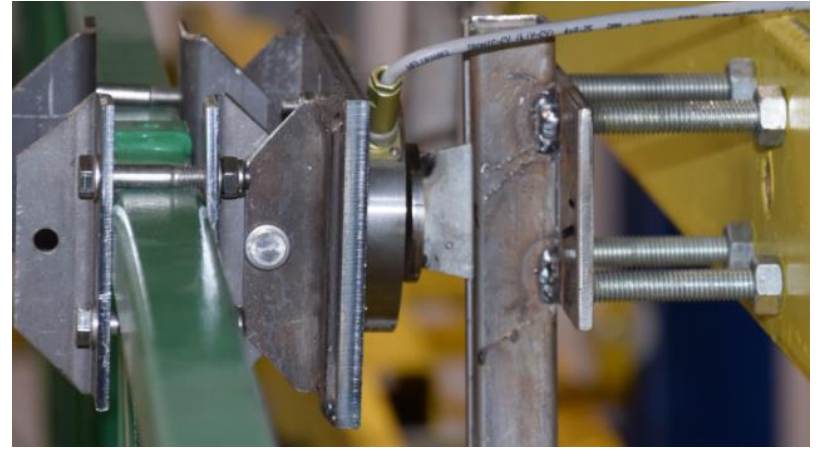

Fig. 7. Technical details of used side supports

The real strength properties of steel and geometry of used sections were determined in destructive tests performed for tubular samples (20) and flat samples (21) taken from section walls. The apparent proportional limit strength $R_{E}, 0.05$, apparent yield strength $R_{e}, 0.2$, ultimate strength $R_{m}$, as well as steel modulus of elasticity $E$ and tube cross-section area $A$ were determined. The average results are shown in Table 1.

Table 1. Steel and sections parameters

\begin{tabular}{|c|c|c|c|c|c|}
\hline $\begin{array}{c}R_{E, 0.05} \\
{[\mathrm{MPa}]}\end{array}$ & $\begin{array}{c}R_{e, 0.2} \\
{[\mathrm{MPa}]}\end{array}$ & $\begin{array}{c}R_{m} \\
{[\mathrm{MPa}]}\end{array}$ & $\begin{array}{c}\mathrm{E} \\
{[\mathrm{GPa}]}\end{array}$ & $\begin{array}{c}\mathrm{A}(\mathrm{RK} \\
30 \times 30 \times 3) \\
{\left[\mathrm{cm}^{2}\right]}\end{array}$ & $\begin{array}{c}\text { A (RK } \\
20 \times 20 \times 2) \\
{\left[\mathrm{cm}^{2}\right]}\end{array}$ \\
\hline 376.6 & 453.7 & 476.2 & 203.8 & 3.05 & 1.37 \\
\hline
\end{tabular}

Before the tests were commenced, measurement of real initial geometrical imperfections of each test model as per standard [13] was performed. Those imperfections did not exceed the admissible values. The maximum measured out-of-plane imperfection of chord reached the value of $10.4 \mathrm{~mm}$ $(L / 670)$. Due to the range of used measurement sensors, higher value of the initial imperfection (than that recommended in the standard L/500) was assumed. In the experimental research a sinusoidal (as more natural) shape of chord imperfection (contrary to [10] and [11]) featuring the maximum value in the middle of the span equal to $e_{0}=40.0 \mathrm{~mm}(L / 175)$, was adopted.

The adopted sinusoidal truss deformation was attained by forced displacement of side supports of the top chord. Said displacement caused a certain truss stress condition and certain support forces $F_{n}{ }^{0.0}$ measured by the force sensors. Then, the truss was loaded in top chord joints by gravitational load $P=1.8 \mathrm{kN}$. This load caused a change of values of support forces marked as $F_{n}{ }^{1.8}$. The differences between both values $\left(F_{n}{ }^{1.8}-F_{n}{ }^{0.0}\right)$ are the sought reactions $F_{n}$ of the truss with imperfections on the transverse roof bracing.

\section{Test results}

The above described tests were performed on 10 identical truss models with adopted conditions of the initial deformation and load. The results achieved were rounded with $0.01 \mathrm{kN}$ accuracy and demonstrated in Table 2. An assumption was made that the relation between the bracing load and the initial truss deformation was symmetric and the results achieved were true also for those joints, for which no reaction measurements were performed. In all tested models change of the bracing load sign nearby joint No 2 was noted. The average vertical truss deflection was noted as $6.58 \mathrm{~mm}$ (deflection caused by load $P$ ).

Table 2. Test results

\begin{tabular}{|c|c|c|c|c|c|c|}
\hline \multirow{2}{*}{$\begin{array}{l}\overline{0} \\
\overline{8} \\
\Sigma\end{array}$} & \multirow{2}{*}{$\begin{array}{l}\text { Support } \\
\text { reaction }\end{array}$} & \multicolumn{5}{|c|}{ Node number } \\
\hline & & 0 & 1 & 2 & 3 & 4 \\
\hline \multicolumn{2}{|c|}{$\begin{array}{c}\text { Assumed } \\
\text { deformation } \\
{[\mathrm{mm}]}\end{array}$} & 0.0 & 15.0 & 28.0 & 37.0 & 40 \\
\hline \multirow[t]{3}{*}{1} & $F_{n}^{0.0}$ & 0.84 & -0.22 & -0.03 & -0.25 & -0.54 \\
\hline & $F_{n}^{1.8}$ & 0.83 & -0.34 & 0.08 & 0.00 & -0.14 \\
\hline & $F_{n}$ & -0.01 & -0.12 & 0.11 & 0.25 & 0.40 \\
\hline \multirow[t]{3}{*}{2} & $F_{n}^{0.0}$ & 0.44 & -0.03 & -0.19 & -0.03 & -0.57 \\
\hline & $F_{n}{ }^{1.8}$ & 0.39 & -0.21 & -0.08 & 0.18 & -0.16 \\
\hline & $F_{n}$ & -0.05 & -0.18 & 0.11 & 0.21 & 0.41 \\
\hline \multirow[t]{3}{*}{3} & $F_{n}{ }^{0.0}$ & 0.42 & -0.06 & -0.03 & -0.06 & -0.66 \\
\hline & $F_{n}^{1.8}$ & 0.35 & -0.24 & 0.04 & 0.15 & -0.24 \\
\hline & $F_{n}$ & -0.07 & -0.18 & 0.07 & 0.21 & 0.42 \\
\hline \multirow[t]{3}{*}{4} & $F_{n}{ }^{0.0}$ & 0.63 & -0.30 & -0.31 & -0.28 & -0.73 \\
\hline & $F_{n}^{1.8}$ & 0.59 & -0.49 & -0.29 & 0.00 & -0.25 \\
\hline & $F_{n}$ & -0.04 & -0.19 & 0.02 & 0.28 & 0.48 \\
\hline \multirow[t]{3}{*}{5} & $F_{n}^{0.0}$ & 0.50 & -0.07 & -0.08 & -0.19 & -0.52 \\
\hline & $F_{n}^{1.8}$ & 0.47 & -0.20 & -0.02 & -0.03 & -0.14 \\
\hline & $F_{n}$ & -0.03 & -0.13 & 0.06 & 0.16 & 0.38 \\
\hline \multirow[t]{3}{*}{6} & $F_{n}^{0.0}$ & 0.54 & -0.01 & -0.38 & -0.52 & -0.67 \\
\hline & $F_{n}^{1.8}$ & 0.50 & -0.16 & -0.29 & -0.32 & -0.30 \\
\hline & $F_{n}$ & -0.04 & -0.15 & 0.09 & 0.20 & 0.37 \\
\hline \multirow[t]{3}{*}{7} & $F_{n}^{0.0}$ & 0.18 & -0.03 & -0.04 & -0.83 & -1.78 \\
\hline & $F_{n}{ }^{1.8}$ & 0.14 & -0.21 & 0.03 & -0.55 & -1.43 \\
\hline & $F_{n}$ & -0.04 & -0.18 & 0.07 & 0.28 & 0.35 \\
\hline \multirow[t]{3}{*}{8} & $F_{n}^{0.0}$ & 0.31 & -0.19 & -0.05 & -0.99 & -0.49 \\
\hline & $F_{n}{ }^{1.8}$ & 0.24 & -0.36 & -0.02 & -0.77 & -0.09 \\
\hline & $F_{n}$ & -0.07 & -0.17 & 0.03 & 0.22 & 0.40 \\
\hline \multirow[t]{3}{*}{9} & $F_{n}^{0.0}$ & 0.19 & -0.24 & -0.07 & -0.37 & -0.65 \\
\hline & $F_{n}^{1.8}$ & 0.13 & -0.40 & -0.11 & -0.12 & -0.31 \\
\hline & $F_{n}$ & -0.06 & -0.16 & -0.04 & 0.25 & 0.34 \\
\hline \multirow[t]{3}{*}{10} & $F_{n}^{0.0}$ & 0.56 & -0.07 & -0.23 & -0.39 & -0.63 \\
\hline & $F_{n}^{1.8}$ & 0.47 & -0.25 & -0.18 & -0.15 & -0.25 \\
\hline & $F_{n}$ & -0.09 & -0.18 & 0.05 & 0.24 & 0.38 \\
\hline
\end{tabular}

Examples of truss with imperfections reactions on the transverse bracing are demonstrated in Figure 8. The results were approximated by the $4^{\text {th }}$ order polynomial function using the least squares method. Also the approximation curve determination coefficient has been presented. 

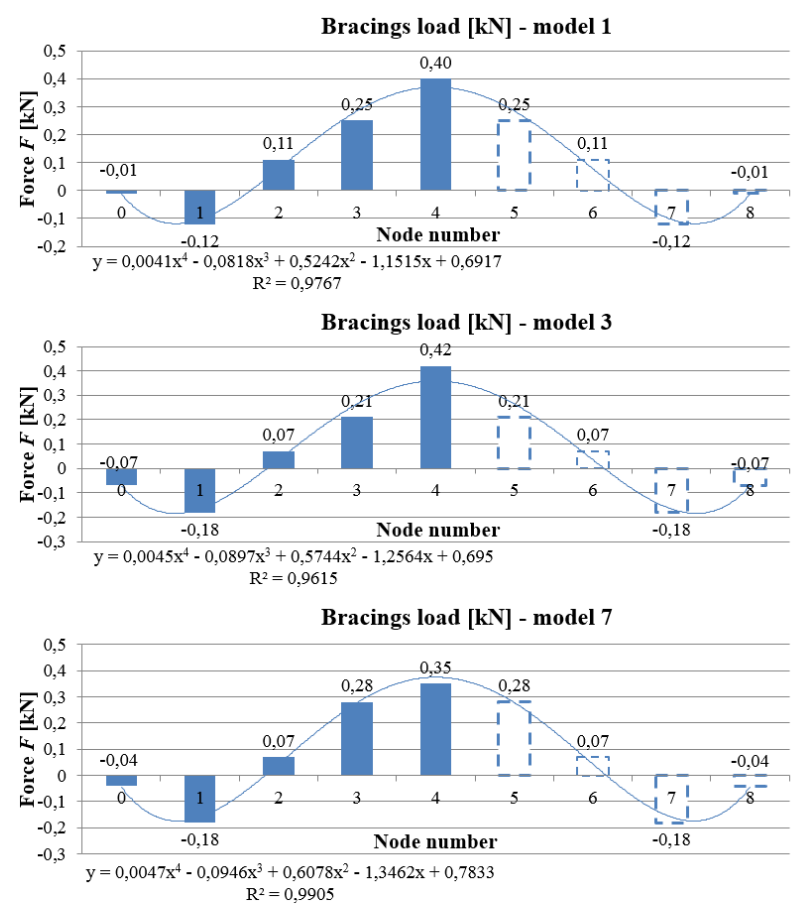

Fig. 8. Examples of measurements results

Empirical values of the transverse bracing were also determined for the analysed truss. Said values were computed in accordance with the experiment assumptions (nodal load $P=1.8 \mathrm{kN}$ and sinusoidal imperfection shape $e_{0}=40.0 \mathrm{~mm}$ ). In [10] and [11] a parabolic shape was considered, but the relations presented therein can be applied, by analogy, in the case of sinusoid half-wave shaped imperfection. Distribution of the normal force in the truss upper chord $N(x)$ and its deformation $y(x)$ as well as load distribution $q(x)$ are presented in Figure 9 whereas particular elements of load $F_{n}$ are demonstrated in Table 3. Figure 9 indicates also the differences between function $q(x)$ in the event of any parabolic and sinusoidal chord imperfection.

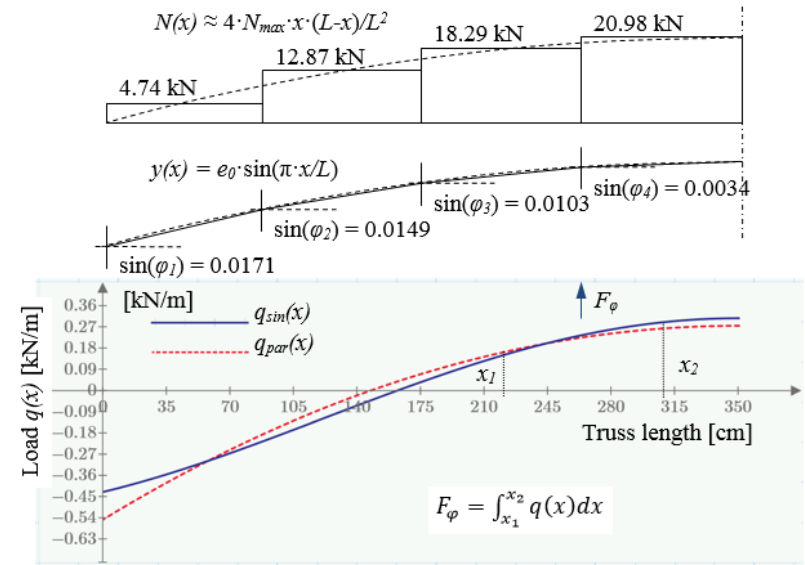

Fig. 9. Functions $N(x), y(x)$ and $q(x)$
Table 3. Empirical analysis

\begin{tabular}{|c|c|c|c|c|c|c|}
\hline \multirow{2}{*}{\multicolumn{2}{|c|}{$F_{n}=F_{\varphi}+F_{\phi}$}} & \multicolumn{5}{|c|}{ Node number } \\
\cline { 2 - 7 } \multicolumn{2}{|c|}{$F_{\varphi}$} & 0 & 1 & 2 & 3 & 4 \\
\cline { 2 - 7 } & As per [10] & -0.08 & -0.11 & 0.00 & 0.12 & 0.14 \\
\cline { 2 - 7 } & As per [11] & -0.17 & -0.19 & 0.03 & 0.20 & 0.26 \\
\hline \multicolumn{2}{|c|}{$F_{\phi}$ as per [10] \& [11] } & 0.00 & 0.05 & 0.08 & 0.11 & 0.12 \\
\hline
\end{tabular}

Comparison of the averaged values of reactions on side supports determined in tests with $F_{n}$ values achieved from empirical relations and standard recommendations [9] are presented in Table 4.

Table 4. Comparison of results

\begin{tabular}{|c|c|c|c|c|c|}
\hline & \multicolumn{5}{|c|}{ Node number } \\
\cline { 2 - 6 } & 0 & 1 & 2 & 3 & 4 \\
\hline As per [9] & 0.12 & 0.12 & 0.12 & 0.12 & 0.12 \\
\hline As per [10] & -0.08 & -0.07 & 0.08 & 0.23 & 0.26 \\
\hline As per [11] & -0.17 & -0.14 & 0.11 & 0.31 & 0.38 \\
\hline Experimental average & -0.05 & -0.17 & 0.05 & 0.22 & 0.39 \\
\hline
\end{tabular}

The reactions computed based on [10] and [11] feature sign change distribution and much higher values of the maximum load than those originating from the standard recommendations. In both cases change of the sign occurs at $L / 4$ distance from the outermost support. The differences between the values computed as per [10] and [11] originate from, among other things, assumption of the imperfection in form of a broken line in the case of [10] and adoption of parabolic function $N(x)$ instead of the step function in the case of [11].

The average test results indicate more than three times higher bracing load in the middle node compared to the standard load. Comparison of the experimental results with the empirically computed load confirms its sign-change character and indicates a more complex distribution resembling a polynomial function. Said distribution has an extremum in the chord span middle. The sign change place is located in the interval between nodes 1 and 2 , but the measured value of the support node load (node 0) is much lower than in the case of any theoretical analyses and indicates existence of additional local extrema in the intervals between nodes 0 and 1 as well as 7 and 8 . The achieved load distributions are compared in Figure 10.

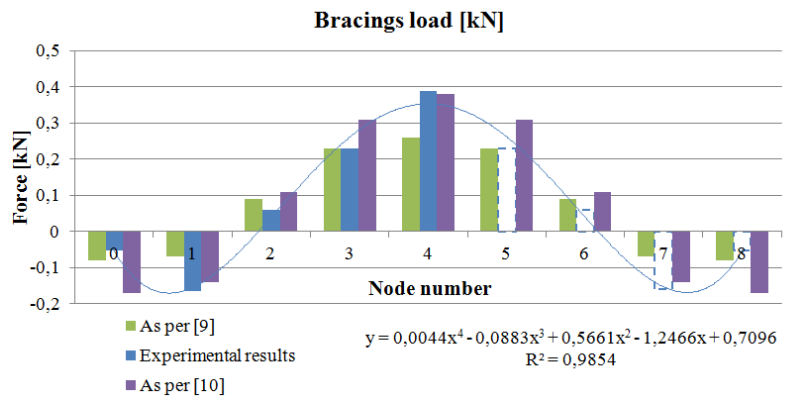

Fig. 10. Comparison of experimental results with theoretical analysis 
Presented comparison shows good qualitative convergence of empirical solutions with tests results. In all analysed methods we have noted a non-uniform distribution of load changing sign at the distance of approximately $L / 4$ from the support. However, certain quantitative divergence could be noted. Bracing load calculated according to [11] has higher values than in the case of calculations as per [10] in each node, and its maximum value $(0.38 \mathrm{kN})$ is very close to the maximum value observed during research work $(0.39 \mathrm{kN})$. At the same time, load value in nodes 0,2 and 3 calculated according to [10] and [11] is higher than the test results. The divergence observed has been explained below based on the numerical analysis.

\section{Numerical analysis}

A numerical model featuring geometry and material characteristic compatible with performed experimental research was developed. Beam MES elements with 6 degrees of freedom in the nodes were used [14]. Accuracy of calculations was enhanced by increasing the number of elements between the nodes in such way so that length of a single MES element did not exceed $150.0 \mathrm{~mm}$. Top chord was modelled using 48 beam elements ( 6 elements between the nodes) whereas the web beams and supporting columns were modelled using 5 beam elements. Rigid connection between web beams and chords was adopted. Calculations were performed using geometrically non-linear analysis (GNLA).

Numerical analyses were performed to review the experimental research. In order to do that, the numerical model was subjected to the same procedure as the experimental model. The truss bracing was modelled as a system of rigid (due to horizontal displacement) side supports in which displacement was forced in accordance with the assumed sinusoidal deformation of the top chord (Tab. 2). Then, the numerical model was loaded with vertical nodal load $P=1.8 \mathrm{kN}$. Reaction of the truss with imperfections on the bracing was defined as a difference of values of support reactions $F_{n}$ before and after model loading with forces $P$. For comparison purposes, support reactions were also determined in the case of direct imperfection modelling (Initial Geometric Imperfection Method). The values achieved are presented in Table 5.

Differences between values achieved in the case of forced support displacement and direct imperfection modelling, originate from occurrence of additional normal forces in the truss chord due to forced displacement of supports. Those forces had quasiparabolic distribution and reached their maximum value $0.67 \mathrm{kN}$ in the span middle and increased respectively force distribution $N(x)$ depending on load $P$.
Table 5. Numerical analysis results

\begin{tabular}{|c|c|c|c|c|c|}
\hline \multirow{2}{*}{$\begin{array}{c}\text { Support } \\
\text { reaction }\end{array}$} & \multicolumn{6}{|c|}{ Node number } \\
\cline { 2 - 6 } & 0 & 1 & 2 & 3 & 4 \\
\hline \multicolumn{7}{|c|}{ Forced support displacement } \\
\hline$F_{n}^{0.0}$ & 0.58 & -0.06 & -0.01 & -0.28 & -0.34 \\
\hline$F_{n}{ }^{l .8}$ & 0.53 & -0.25 & 0.02 & -0.04 & 0.01 \\
\hline$F_{n}$ & -0.05 & -0.19 & 0.03 & 0.24 & 0.35 \\
\hline \multicolumn{7}{|c|}{ Direct imperfection modelling } \\
\hline$F_{n}$ & -0.01 & -0.17 & 0.08 & 0.25 & 0.33 \\
\hline
\end{tabular}

The results achieved are presented in Figure 11. They are compatible with the test results. The differences between particular values of nodal load in the numerical analysis and tests do not exceed $10 \%$. Numerical model deflection caused by applied vertical load is $7.08 \mathrm{~mm}$, whereas that caused by load $P$ and dead weight is $7.31 \mathrm{~mm}$.

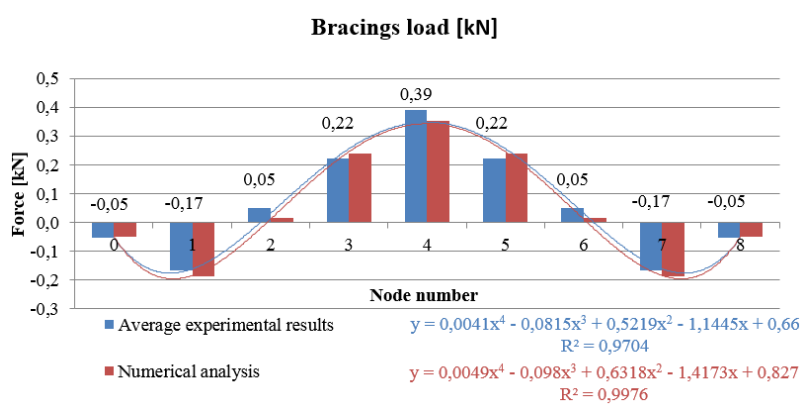

Fig. 11. Comparison of experimental and numerical results

The earlier indicated divergence between relevant values of the empirical and experimental analysis were confirmed also in the numerical analysis. An assumption was made, that they were caused by elastic deformation of the bottom chord, which was supported exclusively at its ends and in the middle of its span. The maximum value of transversal bottom chord deformation, in the case of direct imperfection modelling, was $2.36 \mathrm{~mm}$ (Fig. 12). It has considerable impact on the web members inclination angle and force component $F_{\phi}$ of the bracing load. To confirm this hypothesis, numerical analysis was performed, in which the bottom chord was transversally supported at each joints. Furthermore, a case was analysed, in which no side support would occur lengthwise in the bottom chord. The results achieved are presented in Table 6.

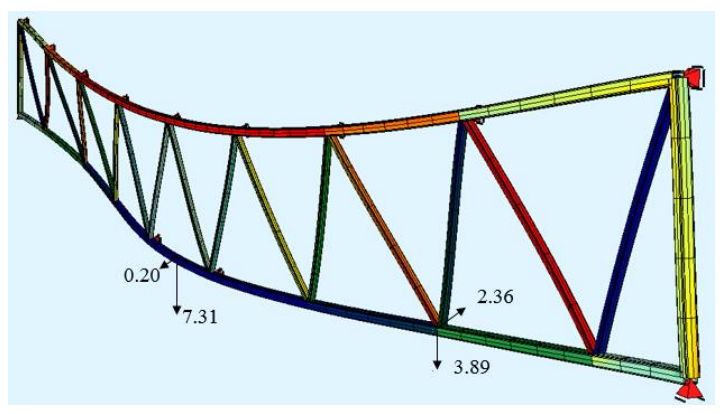

Fig. 12. Numerical model deformation [mm] 
Table 6. Impact of bottom chord support on bracing load

\begin{tabular}{|c|c|c|c|c|c|c|}
\hline $\begin{array}{c}\text { Bottom } \\
\text { chord } \\
\text { support }\end{array}$ & $\begin{array}{c}\text { Support } \\
\text { reaction }\end{array}$ & \multicolumn{6}{|c|}{ Node number } \\
\hline $\begin{array}{c}\text { In each } \\
\text { node }\end{array}$ & $F_{n}^{0.0}$ & 0.71 & -0.23 & -0.10 & -0.27 & -0.20 \\
\cline { 2 - 7 } & $F_{n}{ }^{1.8}$ & 0.63 & -0.30 & -0.01 & -0.04 & 0.07 \\
\cline { 2 - 7 } & $F_{n}$ & -0.08 & -0.07 & 0.09 & 0.23 & 0.27 \\
\hline $\begin{array}{c}\text { No } \\
\text { support }\end{array}$ & $F_{n}{ }^{0.0}$ & 0.06 & -0.01 & 0.01 & -0.06 & 0,01 \\
\hline & $F_{n}{ }^{1.8}$ & 0.29 & -0.12 & 0.04 & 0.04 & 0.13 \\
\cline { 2 - 7 } & $F_{n}$ & 0.23 & -0.11 & 0.03 & 0.10 & 0.12 \\
\hline
\end{tabular}

Comparison of test results with those achieved from numerical analysis and empirical formulae, allows for arriving at the following conclusions pertaining to the considered relations:

- bracing load is a non-uniform and sign-changing load; - maximum load value achieved in the tests $(0.39 \mathrm{kN})$ is by $225 \%$ higher than the value recommended by relevant standard $(0.12 \mathrm{kN})$;

- value of load at the outermost support achieved from the tests and numerical analysis $(-0.05 \mathrm{kN})$ is lower than that originating from empirical analyses by $60 \%$ [10] and $240 \%$ [11];

- omission of bottom chord elastic deformation in the empirical formulae may lead to imprecise load estimation;

- good compatibility of test and numerical analysis results was achieved. Said compatibility is approximately 90\% (Node 4, experimental value $0.39 \mathrm{kN}$ - numerical analysis $0.35 \mathrm{kN}$ ).

It should be noted that said values are proper for the considered test model and their generalisation requires further research.

\section{Conclusions}

Performed experimental research confirms complex distribution of the roof bracing load from a truss girder with imperfections. This distribution features not only higher values of nodal load than in the case of standard recommendation, but also sign-changing distribution dependent not only on the initial imperfection curvature and compression force distribution in the chord, but also on the conditions of support of the bottom chord and its elastic deformation. Therefore, theses presented in [10], [11] and [12] were confirmed experimentally.

It should be stated that considering the complexity of relation between bracing load and truss imperfections, currently standard rules should be verified and application of the simplified model should be abandoned. Considering the fact that designers have now free access to advanced computation programmes, it is recommended that in the event of designing of truss structures with bracings, complete 3D model and direct modelling of imperfections should be applied until proper corrections are introduced into the design standards.

Standard rules, that will be formulated in the future, should take into account not just the factors presented in this paper, but also the possibility of occurrence of initial imperfections in the bottom chord, flexibility of joints and stiffness of the bracing itself.

\section{References}

1. A. Biegus. Trapezoidal sheet as a bracing preventing from out-of-plane buckling, Archives of Civil and Mechanical Engineering, 15, 735-741 (2015)

2. Sz. Pałkowski. On the stabilization of roof purlin with corrugated sheet, Inżynieria i Budownictwo, 9, 473-475 (2017) [in Polish]

3. Sz. Pałkowski. The calculation models of transversal roof bracings, Inżynieria i Budownictwo, 3, p.: 131-133 (2016) . [in Polish]

4. A. Biegus, D. Wojczyszyn. Studies on buckling length of chords for out-of-plane instability, Archives of Civil and Mechanical Engineering, 11/3, 507-517 (2011)

5. J. Jankowska-Sandberg, J. Kołodziej. Experimental study of steel truss lateral-torsional buckling, Engineering Structures, 46, 165-172 (2013)

6. M. Krajewski, P. Iwicki. Analysis of brace stiffness influence on stability of the truss, International Journal of Applied Mechanics and Engineering, 20/1, 97-108 (2015)

7. J. A. Yura. Winter's bracing approach revisited, Engineering structures, 18/10, 821-825 (1996)

8. P. Iwicki. Comparison of classical Winter's bracing requirements of compressed truss chord with stability analysis of 3D truss-model, Proceedings in Applied Mathematics and Mechanics, 9/1, 247-248 (2009)

9. PN-EN 1993-1-1: 2006. Eurocode 3: Design of steel structures. Part 1-1: Genaral rules and rules for building [in Polish]

10. Sz. Pałkowski, M. Piątkowski. On the calculation of lateral roof bracing, Inżynieria i Budownictwo, 4, 210-213 (2014) [in Polish]

11. D. Czepiżak, A. Biegus. Refined calculation of lateral bracing systems due to global geometrical imperfection, Journal of Constructional Steel Research, 19, 30-38 (2016)

12. L. Niewiadomski, J. Zamorowski. The load of transversal bracings resulting from geometric imperfection of single-span trusses of roofs, Proceedings of the 12th International Conference on New Trend in Static and Dynamics of Buildings, Bratislava, Slovakia, (2014) [in Polish]

13. PN-EN 1090-2: 2002. Execution of steel structures and aluminium structures. Technical requirements for steel structures [in Polish]

14. SOFiSTiK - Structural Desktop: User interface of SOFiSTiK software. SOFiSTiK AG. 2008 